Short Communication

\title{
ALTERATION OF PHARMACOKINETIC PARAMETERS OF PENTOXIFYLLINE USING NATURAL MUCOADHESIVE POLYMERS
}

\section{GNANASEKARAN JOHN SELVARAJ, ARUL BALASUBRAMANIAN*, KOTHAI RAMALINGAM}

\author{
Department of Pharmacy Practice, Vinayaka Mission's College of Pharmacy, Vinayaka Mission's Research Foundation (Deemed to be
} University), Salem 636008, Tamilnadu, India

Email: arul1971@yahoo.com

Received: 14 Oct 2019, Revised and Accepted: 12 Nov 2019

\section{ABSTRACT}

Objective: The present study was aimed to alter the pharmacokinetic parameters of the drug pentoxifylline using a novel natural mucoadhesive polymer from two different plants, Manilkara zapotta Linn and Ocimum basilicum Linn.

Methods: The polymer was isolated and six batches of mucoadhesive tablets of pentoxifylline was formulated with 3 different concentrations of each polymer. The best formulation from each of the polymer was selected and administered to rabbits and the plasma drug concentration was compared with the marketed formulation. The pharmacokinetic parameters such as such as $\mathrm{C}_{\max }, \mathrm{t}_{\max }, \mathrm{AUC}$, AUMC, $\lambda_{z}, \mathrm{t}_{1 / 2}$, and MRT were determined.

Results: The plasma drug concentration vs time curve shows the extended-release of pentoxifylline when compared with the conventional marketed formulation. The results show that there is no change in the peak plasma concentration, but the significant difference was observed in $t_{1 / 2}$ which showed approximately 2.5 fold increase from 2.44 to $6.87 \mathrm{~h}$ and the AUC showed five-fold increase from 22.40 to $117.19 \mu \mathrm{g}^{*} \mathrm{~h} / \mathrm{ml}$, and other pharmacokinetic parameters, when compared with the marketed formulation.

Conclusion: The isolated polymer from the plants Manilkara zapotta Linn. and Ocimum basilicum Linn can be used as a carrier for developing mucoadhesive formulations and it alter the pharmacokinetic of pentoxifylline positively.

Keywords: Mucoadhesion, Manilkara zapotta, Ocimum basilicum, Pentoxifylline, Pharmacokinetics

(C) 2020 The Authors. Published by Innovare Academic Sciences Pvt Ltd. This is an open access article under the CC BY license (http://creativecommons.org/licenses/by/4.0/) DOI: http://dx.doi.org/10.22159/ijap.2020v12i1.36080 Journal homepage: https://innovareacademics.in/journals/index.php/ijap

Recently the mucoadhesive drug delivery systems have gained more attention in the pharma profession [1]. Mucoadhesion is a converse of bioadhesion, which is aimed to localize the drugs in the mucosal area of the body. The water-soluble polymers were used for the formulation of mucoadhesive drug delivery systems because they become adhesive during hydration. The mucoadhesive drug delivery systems are aimed to target the drug with increased gastric residence time, bioavailability, minimized the first-pass effect, controlled release of the drug with reduced adverse effects $[2,3]$ The mucoadhesive polymers selected should be non-toxic, nonirritant, non-absorbable, non-covalent, biocompatible, adhesive and economic, in nature [4]. Either natural (gelatin, guar gum and sodium alginate) or synthetic/semi-synthetic (Hydroxypropyl methylcellulose, Carbopol 934 and Sodium carboxy methyl cellulose), may be used alone or in a combination of two or more for the mucoadhesive drug delivery systems [5-9].

Pentoxifylline (PTX) (1-[5-oxohexyl]-3,7-dimethylxantine), an orally active hemorheological drug, which is used for the treatment of intermittent claudication or other circulatory disorders. Its hemorheological effect involves by reducing the blood viscosity and increasing the erythrocyte deformability [10]. PTX is a highly watersoluble drug $(\sim 77 \mathrm{mg} / \mathrm{ml})$. It is well absorbed from the gastrointestinal tract ( $>95 \%$ ), yet the actual amount of drug bioavailable to the body is only about $20 \%$ because of its extensive hepatic first-pass metabolism. Administration of a single dose of extended-release tablets of PTX $(400 \mathrm{mg})$ resulted in a $\mathrm{C}_{\max }$ of 55$300 \mathrm{ng} / \mathrm{ml}$ and $t_{\max }$ values of 2-4 h [11]. Since PTX has a short biological half-life (about $0.4-0.8 \mathrm{~h}$ ), the frequent dosing is necessary to maintain the therapeutic plasma drug concentration.

Manilkara zapota Linn. (MZL), is an evergreen plant belongs to the family Sapotaceae, grows up to $8-15 \mathrm{~m}$ height. It is cultivated throughout the Indian subcontinent including Bangladesh, though it is native to Mexico and Central America. The seeds of MZL are diuretic tonic aperients and febrifuge. The stem bark acts as an astringent, febrifuge [12] and anticancer [13]. The leaves and bark are used to treat cough, cold, dysentery and diarrhea [14].
Antimicrobial and antioxidant activities are also reported from the leaves of MZL $[15,16]$. A natural gum from the seeds of the plant was also isolated [17].

Ocimum basilicum Linn. (OBL) is an erect, almost glabrous herb, belonging to the Lamiaceae family, native to Iran, Afghanistan, and India, which grows to between 30 and $90 \mathrm{~cm}$ high. The leaves are ovate, lanceolate, cucuminate, toothed or entire, glabrous on both surfaces and glandular. When mature, they reach approximately 5 $\mathrm{cm}$ in length, excluding the petiole, which is approximately $2 \mathrm{~cm}$ long. The upper surface is smooth and lustrous; on the lower surface along the midrib and the petiole short, stiff hairs occur sparingly [18]. It represents an important source of essential oil used in food, pharmaceutical, perfumery, and cosmetics industries [19]. Its aromatic leaves are used in fresh or dried forms as a drug in traditional medicine and as a flavoring agent in food and confectionery products as well as beverages $[18,20]$. The seeds of OBL are high in fiber $(22.6 \%)$ and some regions of Asia like Iran and India, basil seeds are frequently included in beverages and desserts for aesthetic purposes as well as a source of dietary fiber [21].

Even though several kinds of research have been made in the area of alteration of pharmacokinetic parameters, mucoadhesive drug delivery systems based on plant-derived polymers also plays a vital role due to their emollient, lack of toxicity, and low cost. In vitro experiments have previously reported that the mucoadhesive polymers of MZL [22] and OBL [23] were suitable agents for the preparation of a controlled release tablet formulation of PTX. So, in this present work, an attempt was made to investigate the effect of these two natural mucoadhesive polymers in the alteration of pharmacokinetic parameters of the PTX.

The seeds of MZL and OBL were purchased from the local vendors of Chennai, Tamilnadu in February 2018. The collected seeds were identified and authenticated by a botanist Dr. S. Balasubramanian, ABS Medicinal garden, Salem. The voucher specimens (MZG-1 and OBG-1) were kept in our museum for future reference. Pentoxifylline was obtained as a gift sample from Shasun Pharmaceuticals, 
Puducherry. Microcrystalline cellulose and magnesium stearate were purchased from Central Drug House (India). Acetone, diethyl ether, and petroleum ether were from Qualigens (India) and sodium hydroxide from E-Merck (India). All the chemicals used were of analytical grade

Three batches of mucoadhesive polymers of Manilkara zapotta Linn. (MAPMZ) and Ocimum basilicum Linn. (MAPOB) were prepared on a laboratory scale by the method of Rao et al. [24]. $20 \mathrm{~g}$ of the seed powders were mixed individually with $200 \mathrm{ml}$ of cold distilled water and the slurry was prepared. Then $800 \mathrm{ml}$ of boiling water was added to the slurry and boiled for another $20 \mathrm{~min}$ with continuous stirring. The solutions were kept overnight to settle the solid matter. The clear solutions were centrifuged for $20 \mathrm{~min}$ at $5000 \mathrm{rpm}$. The supernatant fluids were separated and twice the volume of acetone was added with continuous stirring. The formed precipitates were filtered and washed with petroleum ether and diethyl ether and then dried under vacuum at $50-60^{\circ} \mathrm{C}$. The dried materials were sieved through sieve No 80 and used for the formulation of tablets.

The mucoadhesive tablets of pentoxifylline (MATP) were prepared by using direct compression technique. Pentoxifylline, mucoadhesive polymer, microcrystalline cellulose, magnesium stearate were accurately weighed, mixed/uniformly and this mixture was compressed into tablets by using Elite multi-station punching machine (Erweka) with $10 \mathrm{~mm}$ flat punches. The compression force was adjusted to give tablet hardness in the range of 7 to $11 \mathrm{kp}$. The constituent of the formulation is presented in table 1 .

Table 1: Formulation of mucoadhesive tablets of pentoxifylline

\begin{tabular}{lllllll}
\hline Ingredients & F1 & F2 & F3 & F4 & F5 & F6 \\
\hline Pentoxifylline & 400 & 400 & 400 & 400 & 400 & 400 \\
Microcrystalline cellulose & 152 & 122 & 92 & 152 & 122 & 92 \\
MAPMZ & 30 & 60 & 90 & - & - & - \\
MAPOB & - & - & - & 30 & 60 & 90 \\
Magnesium stearate & 18 & 18 & 18 & 18 & 18 & 18 \\
Total weight (mg) & 600 & 600 & 600 & 600 & 600 & 600 \\
\hline
\end{tabular}

All the quantities are in $\mathrm{mg}$

Female New Zealand white rabbits of either sex or approximately the same age, weighing about 1.5 to $1.6 \mathrm{~kg}$, procured from Sri Venkateswara Enterprises, Bengaluru (Reg No. 237/99), were used for the study. They were housed in separate metallic cages and fed with standard chow diet and water ad libitum. The animals were exposed to an alternate cycle of $12 \mathrm{~h}$ of darkness and light each. Before each test, the animals fasted for at least $12 \mathrm{~h}$. The experimental protocols were subjected to the scrutinization of the Institutional Animal Ethics Committee and were cleared by the same (Approval No. P. COL/20/2019/IAEC/VMCP). The animals were divided into 3 groups each consisting of three. The first group was administered with marketed pentoxifylline tablets $400 \mathrm{mg}$ and the second group treated with the mucoadhesive tablets formulated with MAPMZ (F3) and the third group treated with the mucoadhesive tablets formulated with MAPOB.

The rabbits were administered with the respective formulations along with $100 \mathrm{ml}$ of water. The blood samples were collected into heparinized vacuum tubes at $0.25,0.5,1,2,3,4,6,8,10,12,1620$ and $24 \mathrm{~h}$ following the PTX administration. After collection, the blood samples were centrifuged at $1000 \mathrm{rpm}$ for $10 \mathrm{~min}$ at room temperature $\left(25^{\circ} \mathrm{C}\right)$; followed by direct transfer into microcentrifuge tubes and stored at $-70^{\circ}$ $\mathrm{C}$ until analysis. The amount of food and water intake for each animal was standardized during the sampling day.

A stock solution of PTX $(40 \mu \mathrm{g} / \mathrm{ml})$ was prepared by dissolving in double-distilled water. The working standard solutions of PTX were produced by diluting the stock solutions with blank rabbit plasma (1:1). The ten calibration standards of PTX were prepared independently. The concentration range of PTX was 10 to $2000 \mathrm{ng} / \mathrm{ml}$. All stock solutions, stored at $4{ }^{\circ} \mathrm{C}$, were stable for at least one month without any degradation. The liquid-liquid extraction method was used for the sample preparation of PTX. $0.1 \mathrm{ml}$ of $1 \mathrm{M}$ sodium hydroxide and $7 \mathrm{ml}$ of dichloromethane were added to $1 \mathrm{ml}$ of plasma. The mixture was vortexed for $30 \mathrm{sec}$ and centrifuged at $3000 \mathrm{rpm}$ for $15 \mathrm{~min}$. The upper layer was removed and the organic phase was placed into another test tube and evaporated to dryness under a flow of nitrogen stream at $37{ }^{\circ} \mathrm{C}$. The residue was redissolved in $0.2 \mathrm{ml}$ of the mobile phase (acetonitrile: water, 28:72, v/v) and $30 \mu \mathrm{l}$ of this solution was injected directly on to the column. The plasma extract was stable for at least two days when kept at $4{ }^{\circ} \mathrm{C}$.

The PTX concentrations in plasma were assayed using a validated high performance liquid chromatography with ultraviolet detection (UV-HPLC) [25, 26]. A high-performance liquid chromatograph (Hewlett-Packard Series 1050) was equipped with a variable wavelength UV detector. The analytical column was a reverse phase,
$300 \times 3.9$ mm I.D., RP-18 $\mu$ m Hyperbond (Hypersil). The detection was at $274 \mathrm{~nm}$. The mobile phase was a combination of acetonitrile: water $(28: 72, \mathrm{v} / \mathrm{v})$ and the flow rate was $1 \mathrm{ml} / \mathrm{min}$. The retention time of PTX was 5.15 min (retention volume $5.15 \mathrm{ml}$ ). The bioanalytical method was specific with no interfering impurities at the retention time of PTX. The linear calibration model was constructed between peak-height and concentration of PTX in plasma samples.

The method exhibited a linearity of response over a range of 10$2000 \mathrm{ng} / \mathrm{ml}$ for PTX (r2=0.998). Limit of detection and limit of quantification were found to be 5 and $10 \mathrm{ng} / \mathrm{ml}$, respectively. Quality control samples at three levels, low $(30 \mathrm{ng} / \mathrm{ml})$, middle $(600$ $\mathrm{ng} / \mathrm{ml})$ and high $(1600 \mathrm{ng} / \mathrm{ml})$ for PTX were used during routine analysis. The within-batch precision ranged from 2.30 to $5.35 \%$ and accuracy ranged from 99.6 to $103 \%$. The between-batch precision and accuracy ranged from 4.43 to 6.85 and 102 to $105 \%$, respectively. The stability of the samples under frozen conditions, at room temperature, and during the freeze-thaw cycle was also determined. The accuracy and precision for calibration curve standards and quality samples in all bioanalytical methods met the acceptance criteria as per FDA guidelines.

Pharmacokinetic evaluation non-compartmental modeling was used to estimate PTX pharmacokinetic parameters after single-dose administration. The PTX plasma concentration vs time data were evaluated by using PKSolver. Pharmacokinetic parameters such as maximum PTX concentration $\left(\mathrm{C}_{\max }\right)$ in plasma, the time that $\mathrm{C}_{\max }$ occurred $\left(\mathrm{t}_{\max }\right)$, area under the plasma concentration time curve from 0 to $24 \mathrm{~h}\left(\mathrm{AUC}_{0-24}\right)$ and 0 to infinity $\left(\mathrm{AUC}_{0-\infty}\right)$, elimination rate constant $\left(\lambda_{z}\right)$, biological half-life $\left(t_{1 / 2}\right)$, Apparent volume of distribution during terminal phase after non-intravenous administration $(\mathrm{Vz} / \mathrm{F})$, Apparent total clearance of the drug from plasma after oral administration $(\mathrm{Cl} / \mathrm{F})$ and mean residence time (MRT) were determined.

The area under the plasma concentration versus time curve from 0 to $24 \mathrm{~h}\left(\mathrm{AUC}_{0-24}\right)$ was assessed using the linear trapezoidal methodology and was extrapolated to infinity $\left(\mathrm{AUC}_{0-\infty}\right)$. The maximum plasma concentration $\left(\mathrm{C}_{\max }\right)$ and time to reach $\mathrm{C}_{\max }\left(\mathrm{t}_{\max }\right)$ for PTX were directly obtained from the individual observed data. The terminal phase elimination rate $(\lambda z)$ was estimated using a loglinear regression of the observed plasma concentration point in the terminal phase, and the elimination half-life $\left(\mathrm{t}_{1 / 2}\right)$ was calculated as $0.693 / \lambda z$. The apparent total clearance $(\mathrm{Cl} / \mathrm{F})$ and volume of distribution $(\mathrm{Vz} / \mathrm{F})$ were calculated using the formulas dose/AUC ${ }_{0-\infty}$ and dose $/\left(\lambda \mathrm{z} * \mathrm{AUC}_{0-\infty}\right)$, respectively. 
Each experiment was repeated at least three times. The results are expressed as the mean \pm SD One-way analysis of variance was used to test the statistical significance of differences among groups. Statistical significance of the differences of the means was determined by Student's t-test.

Pentoxifylline is a synthetic dimethyl xanthine derivative prescribed for complications of peripheral vascular diseases. Although pentoxifylline is almost completely absorbed, it undergoes significant first-pass metabolism resulting in a bioavailability of $20 \%$ and frequent dosing is necessary [27]. Mucoadhesive drug delivery systems are used to increase the bioavailability of drugs. Natural polymers are preferred over synthetic and semi-synthetic polymers due to their low cost, non-toxic, emollient, free availability and nonirritating nature [28-30]. Even though many polymers are available, a search for new polymers still interesting to get more efficacious polymers with less toxic. So in this present work, an attempt was made to study the effect of mucoadhesive polymers in the modification of pharmacokinetic properties of PTX.

The mucilage was isolated from the seeds of M. zapota and $O$. basilicum by the method of Rao et al. [24]. The mucoadhesive tablets of pentoxifylline were formulated by using three different concentrations of MAPMZ and MAPOB at 5, 10 and $15 \%$. Six formulations of $\mathrm{F} 1$ to $\mathrm{F} 6$ were formulated and evaluated for the mucoadhesive property and in vitro release. From the earlier studies $[22,23]$ it was proved that the tablets formulated with the polymers showed good mucoadhesive strength in rabbit buccal mucosa. One best formulation from each of the polymers was selected for the pharmacokinetic studies. Formulation F3 showed the release of $99.44 \%$ of cumulative release and the formulation F6 showed 99.84 $\%$ release at 12 and $10 \mathrm{~h}$ respectively. So these two formulations (F3 and F6) were selected for the pharmacokinetic studies in rabbits.

Female New Zealand white rabbits of either and the same age, weighing about 1.5 to $1.6 \mathrm{~kg}$ were used for the study. The formulations F3, F6, and marketed formulation were administered to rabbits along with $100 \mathrm{ml}$ of water. The drug concentrations in plasma after the administration PTX in 3 groups were followed for $24 \mathrm{~h}$. The PTX concentrations in plasma were assayed using a validated high-performance liquid chromatography with the UVHPLC method. The mean plasma concentration versus time profiles for PTX after a single oral dose of PTX is shown in fig. 1. The pharmacokinetic parameters were calculated by using PKSolver. The results are given in table 2 .

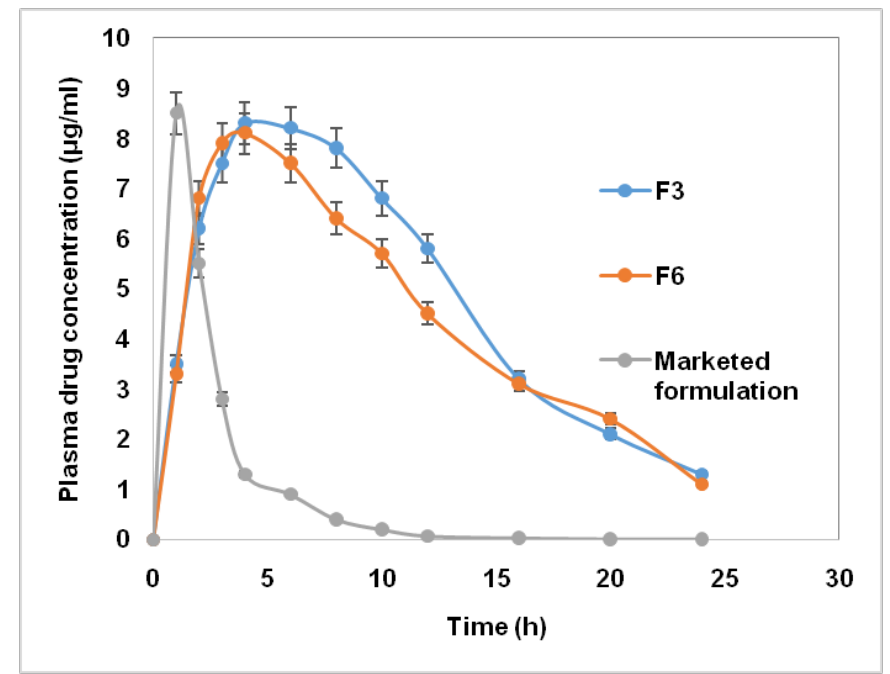

Fig. 1: Mean plasma concentration of PTX after a single oral dose (mean $\pm S D ; n=3$ )

Table 2: Non-compartmental extravascular pharmacokinetic parameters after single-dose administration of PTX on rabbits

\begin{tabular}{llll}
\hline Parameters & Values & & \\
\cline { 2 - 4 } & F3 & F6 & Marketed formulation \\
\hline$\lambda_{\mathrm{z}}\left(\mathrm{h}^{-1}\right)$ & 0.1187388 & 0.1008491 & 0.2838929 \\
$\mathrm{t}_{1 / 2}(\mathrm{~h})$ & 5.8375792 & 6.8731144 & 2.4415796 \\
$\mathrm{~T}_{\max }(\mathrm{h})$ & 4 & 4 & 1 \\
$\mathrm{C}_{\max }(\mu \mathrm{g} / \mathrm{ml})$ & 8.351333 & 8.212667 & 8.499333 \\
$\mathrm{AUC}_{0-\mathrm{t}}\left(\mu \mathrm{g}^{*} \mathrm{~h} / \mathrm{ml}\right)$ & 117.18833 & 107.31067 & 22.408331 \\
$\mathrm{AUC}_{0-\infty}(\mu \mathrm{g} * \mathrm{~h} / \mathrm{ml})$ & 128.27148 & 118.14864 & 22.440033 \\
$\mathrm{AUMC}_{0-\infty}\left(\mu \mathrm{g}^{2} \mathrm{~h}^{2} / \mathrm{ml}\right)$ & 1460.5715 & 1370.4631 & 65.788487 \\
$\mathrm{MRT}(\mathrm{h})$ & 11.386565 & 11.599482 & 2.9317465 \\
$\mathrm{Vz} / \mathrm{F}(\mathrm{L})$ & 26.262569 & 33.57062 & 62.788764 \\
$\mathrm{Cl} / \mathrm{F}(\mathrm{L} / \mathrm{h})$ & 3.118386 & 3.3855657 & 17.825286 \\
\hline
\end{tabular}

(All values are calculated from the mean of Plasma PTX concentration; $\mathrm{n}=3$ )

The absorption of PTX is rapid in marketed formulation than the test formulations; the mean $t_{\max }$ of the marketed formulation was $1 \mathrm{~h}$, while in the formulation F3 and F6, the mean $\mathrm{t}_{\max }$ was around $4 \mathrm{~h}$. This shows that the mucoadhesive tablets formulated with MZL and OBL were effective in delaying the peak plasma concentration of PTX. The peak plasma concentrations $\left(\mathrm{C}_{\max }\right)$ of PTX were found to be $8.35,8.21$ and $8.50 \mu \mathrm{g} / \mathrm{ml}$, respectively for the $\mathrm{F} 3, \mathrm{~F} 6$, and marketed formulation. It indicates there is no significant change in the peak plasma concentration when it is given as controlled release formulation or a conventional marketed release formulation, which assures the formulations F3, and F6 are in the same therapeutic window of the marketed formulation. The $\mathrm{K}_{\mathrm{el}}$ values were found to be $0.119,0.101$ and $0.284 \mathrm{~h}^{-1}$ calculated from the slope of the plasma concentration-time data. A decrease in elimination rate constant of formulations F3 and F6 indicated the slow/sustained release of the drug PTX in rabbit [31]. 
$\mathrm{AUC}_{0-\infty}$ in plasma were $128.271,118.149$ and $22.440 \mu \mathrm{g} . \mathrm{h} / \mathrm{ml}$, respectively, for the formulations F3, F6 and marketed formulation, which indicated the increased bioavailability of the mucoadhesive formulation. The AUC of the formulation F3 and F6 was increased almost 5-6 fold, which shows the sustained release of the drug PTX for an extended period. The elimination rate of PTX was relatively fast with a $t_{1 / 2}$ of $5.84,6.87$ and $2.44 \mathrm{~h}$. The $\mathrm{t}_{1 / 2}$ values were found to vary widely; similar results were reported by Beerman et al., [11] who obtained a mean $t_{1 / 2}$ value of $3.43 \mathrm{~h}$. The other parameters like AUMC also found to be higher in the F3 and F6 formulations. The controlled release characteristics of the formulated mucoadhesive tablets were reflected in the MRT. The MRT was noticeably increased following oral administration of the PTX mucoadhesive formulations $(11.387,11.599 \mathrm{~h})$ as compared to the conventional marketed formulation $(2.93 \mathrm{~h})$.

PTX is hepatically metabolized by hydroxylation and demethylation to six renally excreted metabolites [32]. The presence of a high concentration of PTX may alter the mechanism of metabolizing enzymes by saturation, which may lead to increased bioavailability. On the other hand, PTX is reduced extrahepatically to form an intermediate metabolite known as hydroxy-PTX which may be converted back to the parent compound or possibly be metabolized further [33]. Pentoxifylline has a wider therapeutic range (1200$2000 \mathrm{mg} /$ day) in humans for oral application [34]. In this present study, each animal was administered with $400 \mathrm{mg}$ of PTX either formulated with MZL or OBL and the marketed formulation for the evaluation of bioavailability and other pharmacokinetic parameters.

The significant difference was observed in all the pharmacokinetic parameters between both the formulations with the marketed formulation. Thus, the results of the present study clearly indicated the applicability of mucoadhesive polymer in the alteration of pharmacokinetic parameters of the drug PTX. We concluded that enhancement in the bioavailability of PTX would suggest that mucoadhesive tablet formulation could be used to improve the oral bioavailability of PTX.

The pharmacokinetic study of the formulated mucoadhesive tablets of PTX in rabbits was carried out in view of the alteration of the pharmacokinetic parameters. The tablets were formulated with the mucoadhesive polymers MZL and OBL. The plasma drug concentration versus time interval was estimated by UV-HPLC. The increase in $t_{\max }$ value and decrease in $\mathrm{C}_{\max }$ value in case of the formulated tablet F3 and F6 from the values of the conventional marketed formulation of PTX, revealed that the MZL and OBL polysaccharides can be used as a carrier for developing mucoadhesive formulations, and those can alter the pharmacokinetic of PTX positively.

\section{AUTHORS CONTRIBUTIONS}

All authors have contributed equally.

\section{CONFLICTS OF INTERESTS}

All authors have none to declare.

\section{REFERENCES}

1. Jimenez Castellanos MR, Zia H, Rhodes CT. Mucoadhesive drug delivery systems. Drug Dev Ind Pharm 1993;19:143-94.

2. Ahuja A, Khar RK, Ali J. Mucoadhesive drug delivery systems. Drug Dev Ind Pharm 1997;23:489-515.

3. Nagai T MY. Advances in drug delivery, mucosal adhesive dosage forms. Pharm Int 1985;6:196-200.

4. Gayot A. Bioadhesive polymers. J Pharm Belg 1985;40:332-8.

5. Shin SC, Kim JY. Enhanced permeation of triamcinolone acetonide through the buccal mucosa. Eur J Pharm Biopharm 2000;50:217-20.

6. Cilurzo F, Minghetti P, Selmin F, Casiraghi A, Montanari L. Polymethacrylate salts as new low-swellable mucoadhesive materials. J Controlled Release 2003;88:43-53.

7. Han Gon C, Jac Hee J, Chul Soon Y, Chong Dal R, Mi Kyung L, Jeong Hee H, Kyung-mi P C-KK. Formulation and in vitro evaluation of omeperazole buccal adhesive tablet. J Controlled Release 2000;68:405-12.
8. Miyazaki S, Kawasaki N, Nakamura T, Iwatsu M, Hou WM, Attwood D. Oral mucosal bioadhesive tablets of pectin and HPMC: in vitro and in vivo evaluation. Int $\mathrm{J}$ Pharm 2000;204:127-32.

9. Shah HP, Prajapati ST, Patel C. Gastroretentive drug delivery systems: from conception to commercial success. J Crit Rev 2017;4:10-21.

10. Ward A, Clissold SP. Pentoxifylline. A review of its pharmacodynamic and pharmacokinetic properties, and its therapeutic efficacy. Drugs 1987;34:50-97.

11. Beermann B, Ings R, Mansby J, Chamberlain J, McDonald A. Kinetics of intravenous and oral pentoxifylline in healthy subjects. Clin Pharmacol Ther 1985;37:25-8.

12. Morais PLD, Miranda MRA, Lima LCO, Alves JD, Alves RE, Silva JD. Cell wall biochemistry of sapodilla (Manilkara zapota) submitted to 1-methylcyclopropene. Brazilian J Plant Physiol 2008;20:85-94.

13. Osman MA, Rashid MM, Aziz MA, Habib MR, Karim MR. Inhibition of ehrlich ascites carcinoma by Manilkara zapota $\mathrm{L}$. stem bark in swiss albino mice. Asian Pac J Trop Biomed 2011;1:448-51.

14. Chanda SV NK. Antioxidant capacity of Manilkara zapota L. leaves extracts evaluated by four in vitro methods. Nat Sci 2010;8:260-6.

15. Nair R, Chanda S. Antimicrobial activity of Terminalia catappa, Manilkara zapota and Piper betel leaf extract. Indian J Pharm Sci 2008;70:390-3

16. Kaneria M, Baravalia Y, Vaghasiya Y, Chanda S. Determination of antibacterial and antioxidant potential of some medicinal plants from saurashtra region, India. Indian J Pharm Sci 2009;71:406-12.

17. Sudarshan Singh, Sunil B Bothara. Manilkara zapota (Linn.) seeds: a potential source of natural gum. ISRN Pharm 2014:1-10.

18. Prakash V. Leafy spices. CRC Press; 1990. p. 114.

19. Simon J, Quinn J, Murray R. Basil: a source of essential oil. In: Advances in new crops. J Janick, Simon J. editors. Timloer Press: Portland OR; 1990. p. 484-9.

20. Marotti M, Piccaglia R, Giovanelli E. Differences in essential oil composition of basil (Ocimum basilicum L.) Italian cultivars related to morphological characteristics. J Agric Food Chem 1996;44:3926-9.

21. Mathews S, Singhal RS, Kulkarni PR. Ocimum basilicum: a new non-conventional source of fibre. Food Chem 1993;47:399-401.

22. Gnanasekaran J, Arul B, Kothai R. Development of mucoadhesive tablet of pentoxifylline using a natural polymer from Manilkara zapota linn. Int J Appl Pharm 2019;11:88-91.

23. Balasubramanian A, John Selvaraj G, Ramalingam K. Application of novel natural mucoadhesive polymer in the development of pentoxifylline mucoadhesive tablets. Int J Appl Pharm 2019;11:37-41.

24. Rao PS SH. Tamarind. In: Industrial Gums. 2nd edn. RL W. editor. Academic Press, New York; 1973. p. 369-411.

25. Yan KS, Yan TX, Guo H, Li JZ, Wei LL, Wang C. Evaluation of transdermal permeability of pentoxifylline gel: in vitro skin permeation and in vivo microdialysis using wistar rats. Drug Discovery Ther 2007;1:78-83.

26. Teksin ZS, Agabeyoglu I, Yamac K. Bioavailability of pentoxifylline-chitosan. J Bioequiv Available 2009;1:115-20.

27. Hussein $\mathrm{AH}$. Formulation and evaluation of sustained release tablets of pentoxifylline using okra extract as a novel retardant. Int J Pharm Pharm Sci 2014; 7:204-8.

28. Saikia T, Ali J, Das B. Isolation and characterization of tamarind seed polysaccharide-a natural lrease retardant. Int J Curr Pharm Res 2017;9:114-7.

29. Pandey S, Shah RR, Gupta A, Arul B. Design and evaluation of buccoadhesive controlled release formulations of prochlorperazine maleate. Int J Pharm Pharm Sci 2016;8:375-9.

30. Nishad K, Arul B, Rajasekaran S. Design and comparative evaluation of clarithromycin gastric bioadhesive tablets by exvivo and in vivo methods. Asian J Pharm Clin Res 2018;11:24856. 
31. Harris D, Fell JT, Taylor DC, Lynch J, Sharma HL. GI transit of potential bioadhesive systems in the rat. J Controlled Release 1990;12:55-65.

32. Smith RV, Waller ES, Doluisio JT, Bauza MT, Puri SK, Ho I. Pharmacokinetics of orally administered pentoxifylline in humans. J Pharm Sci 1986;75:47-52.
33. Mauro VF, Mauro LS, Hageman JH. Alteration of pentoxifylline pharmacokinetics by cimetidine. J Clin Pharmacol 1988;28: 649-54.

34. Antignani PL, Todini AR, Saliceti F, Pacino G, Bartolo M. Results of clinical, laboratory and haemorheological investigations of the use of pentoxifylline in high doses. Pharmatherapeutica 1987;5:50-6. 